SANDIA REPORT SAND81-1522 • Unlimited Release • UC-11

Printed April 1982

\title{
The Modular Airborne Remote Sampling and Sensing System (MARSSS)
}

Robert O. Woods

\section{Prepared by}

Sandia National Laboratories

Albuquerque, New Mexico 87185 and Livermore, California 94550

for the United States Department of Energy

under Contract DE-AC04-76DP00789 
Issued by Sandia National Laboratories, operated for the United States Department of Energy by Sandia Corporation.

NOTICW: This report was prepared as an account of work sponsored by an agency of the United States Government. Neither the United States Government nor any agency thereof, nor any of their employees, nor any of their contractors, subcontractors, or their employees, makes any warranty, express or implied, or assumes any legal liability or responaibility for the accuracy, completeness, or usefulness of any information, apparatus, product, or process disclosed, or represents that its use would not infringe privately onned

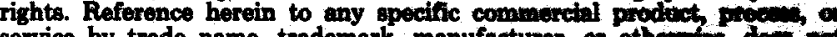
service by trade name, trademark, manufacturer, or otherwtos, dow not necessarily constitute or imply its endorsement, recommendation, or favoring by the United States Government, any agency thereof or any of their by the United States Government, any agency thereof or any of their not necessarily state or reflect those of the United States Government, any agency thereof or any of their contractors or subcontractors.

Printed in the United States of America

Available from

National Technical Information Service

U.S. Department of Commerce

5285 Port Royal Road

Springfield, VA 22161

NTIS price codes

Printed copy: A02

Microfiche copy: A01 
SAND81-1522

THE MODULAR AIRBORNE REMOTE

SAMPLING AND SENSING SYSTEM

(MARSSS)

R. O. Woods

Sandia National Laboratories

Albuquerque, NM 87185

\section{ABSTRACT}

Sandia is developing a modular airborne instrumentation system for the Environmental Protection Agency. This system will allow flexibility in the choice of instruments by standardizing mountings, power supplies and sampling modes. The objective is to make it possible to perform aerial surveys from chartered aircraft that have not been adapted in a more than superficial manner. It will also allow the experimenter to tailor his choice of instruments to the specific problem. Since the equipment will have a stand-alone capability, it can be applied to other problems such as long-term unattended use at remote locations or in toxic or otherwise hazardous environments.

*Presented at APCA Specialty Conference on: In-Situ Air Quality Monitoring from Moving Platforms, San Diego, CA, January 18-21, 1982 . 
CONTENTS

Page

Introduction

7

Standardization $\quad 13$

$\begin{array}{ll}\text { Aircraft Interface } & 14\end{array}$

Data Acquisition and Control system 17

$\begin{array}{ll}\text { Prototype System Components } & 19\end{array}$

F IGURES

1 System Components 9

2 Applications 10

3 Aircraft Installations 16

4 Computer Systems $\quad 18$

TABLE

1 System Components 20 


\section{INTRODUCTION}

The objective of the program described here is to produce an instrument system that is man-portable, self-contained, and capable of being installed in chartered aircraft that have not been especially modified for the installation. An important part of the effort will be to repackage all equipment in such a way that the instruments can be permuted at the discretion of the experimenter. This will entail standardizing package geanetries and electrical characteristics such as power supply voltages and data/command bus formats.

Our effort has been motivated by the need to reduce the cost of making airborne surveys. As it is done today, this often involves making the semi-permanent installation of instruments in aircraft which are then largely committed to the application. This is expensive not only because of the need to render the installation airworthy and in conformance with FAA regulations, but also because it frequently involves tieing up expensive aircraft and, in some cases, keeping them idle while waiting for meteorological or other conditions to become favorable to the projected experiment. Response to unexpected events such as volcanic eruptions takes place on an ad hoc basis because it is not practical to maintain a fleet of instrumented aircraft whose only use would be to respond to unforeseen events.

One scenario that we envision for the use of the MARSss would be for an experimenter to tailor a selection of instruments for a site-specific survey, travel to the scene by commercial airline (with the instruments being shipped as baggage), then 
perform the necessary experiments using an airplane chartered from a local operator. This implies that the system will be designed for use in a readily available type of aircraft and that installation will involve no more than a few hours of work by an aircraft mechanic.

The fact that packages will be standardized in the interest of allowing easy interfacing of the instruments will have beneficial side effects similar to those following from the wide adoption of nuclear instrumentation module (NIM) standards for nuclear instrumentation. (In fact, we plan to use NIM components-such as power supplies--wherever possible.)

The overall system is shown (in concept only) in Figure 1. It should be stressed that this serves to identify the components of the system and does not represent a realistic geometry. In addition to the sensors themselves, the assembly will include a microcomputer for data logging and instrument control as well as for driving a remote display. It will also allow a selection of several different power supplies, a local display to be used for calibration and checkout, navigational equipment, pumping, and a separable calibration system. The sensor modules are sketched in a way that stresses the fact that they can be "stacked" in any permutation at the option of the experimenter.

Since the very nature of the system is such that it will be readily portable and capable, if needed, of operating in an interactive mode but without the operator actually touching the equipment, it will readily lend itself to applications other than airborne ones. Figure 2, also highly schematic, shows some of these. 


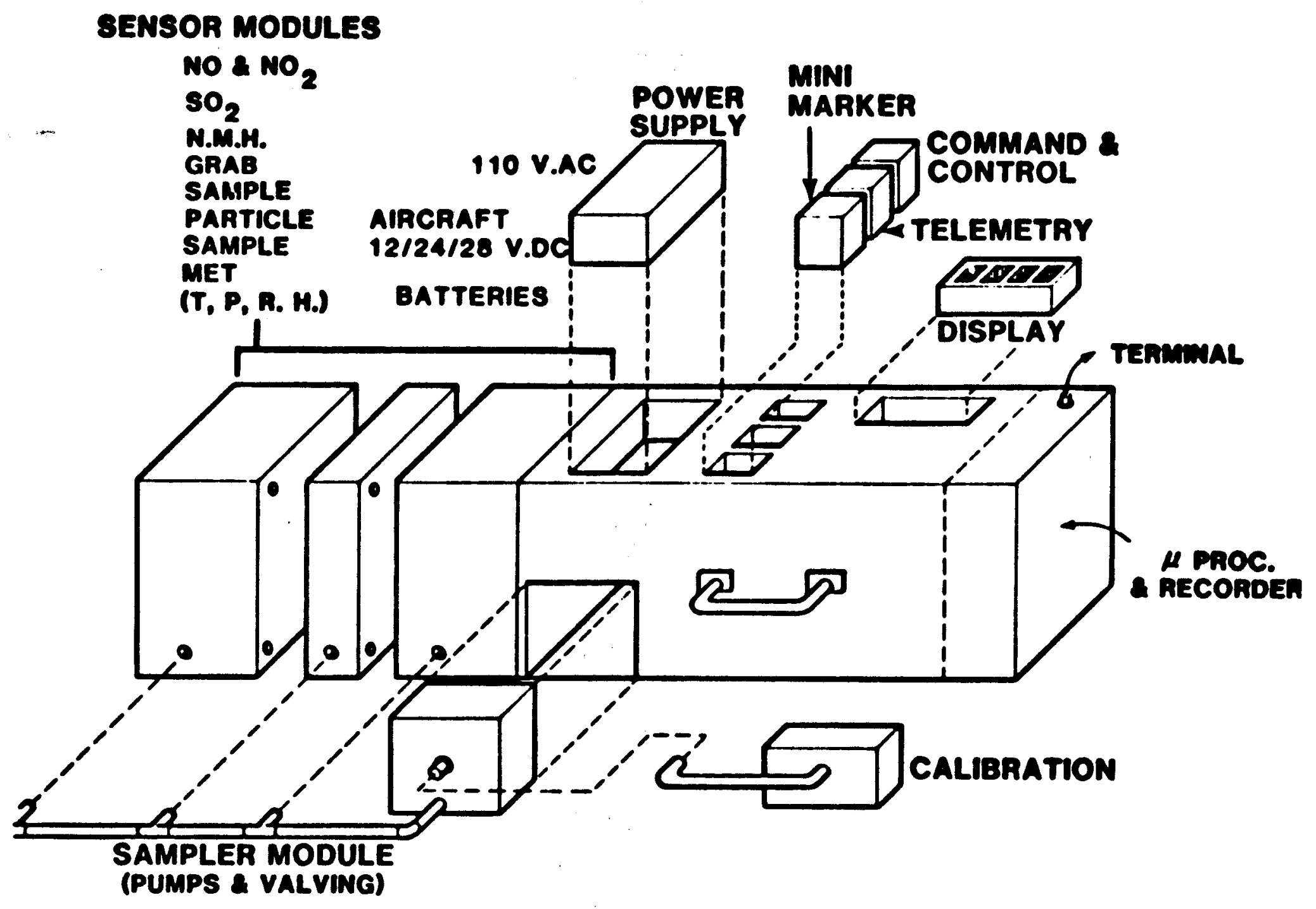

Figure 1. System Components 


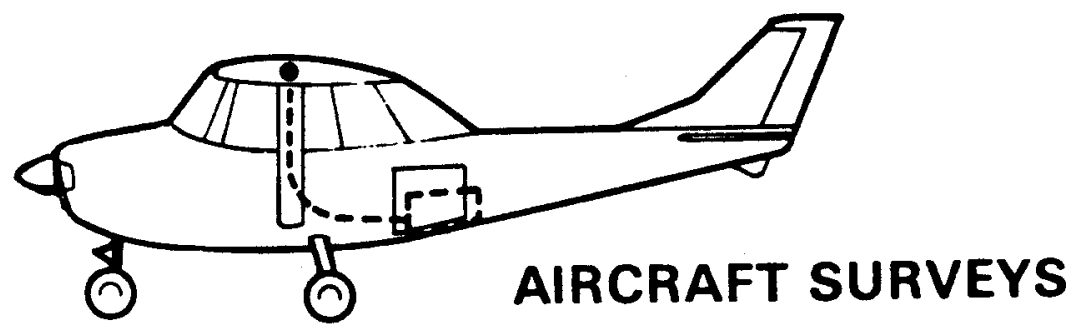

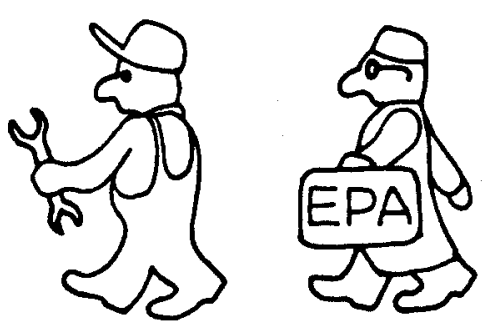

PERSONNEL EXPOSURE

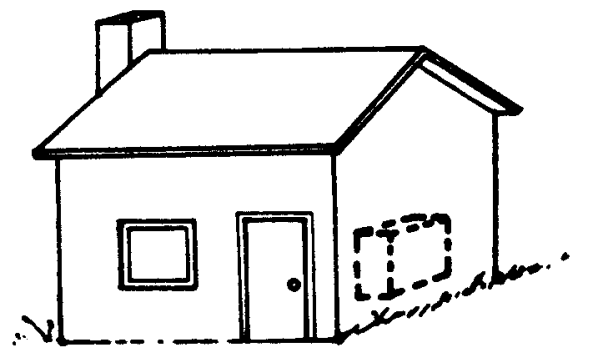

INDOOR MONITORINGENERGY CONSERVATION EFFECTS

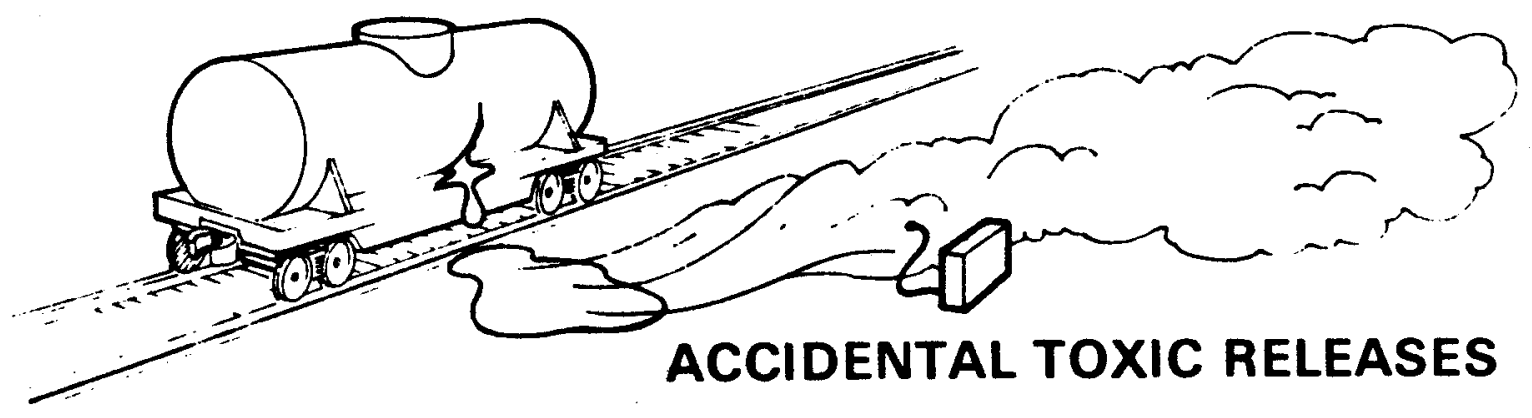

Gin Sandia National Laboratories

Figure 2. Applications 
The cartoon shows, among other things, use of the system to monitor the exposure to different environments of a worker who moves about within, say, a chemical processing plant. In such an application, pollutant concentrations are measured as more than point functions. Varying exposures that might involve synergistic effects are measured on the worker's actual track and for realistic times. In this application a remote capability is not needed, but a portable--and to some degree ruggedized--instrument system is required. It seems likely that the equipment will be transported on a dolly, rather than carried as shown in this fanciful sketch. Another application that will require little reconfiguring from the airborne is that of long-term monitoring of indoor air quality. The only change in support equipment needed here is the replacement of the battery power supply with an AC interface. The system's ability to function without operator attention will allow it to be emplaced in a residence or other structure and to monitor changes in air quality, e.g., the accumulation of solvent vapors, combustion products, and naturally occurring species such as Radon. Great interest is currently being expressed in these effects as they are brought about by energy conservation measures.

The monitoring of accidental toxic releases can be performed more safely than is currently possible by allowing an investigator (equipped with life support equipment if necessary) to emplace the equipment near the source and then leave. Vans intended for such applications exist, but they require an on-board crew who must remain exposed to the harmful environment. 
That the system will be easily transportable and hence easily made avilable for loan, and the fact that it will be capable of operating with a minimum of bias caused by the technique of individual operators, will render it suitable for monitoring and enforcing applications. A relatively few systems, if strategically deployed, could be made available on short notice anywhere in the country. Since externally controlled functions such as zero adjustments, checking of span, and range selection will be automated rather than depending on the technique of the experimenter, results will be more reproducible. This will be true not only between one instrument and another but also for the same instrument in the hands of different operators. This will make the data more directly comparable when taken at one site and then at another. It will also provide greater credibility in cases where this is cause, perhaps legal, to closely scrutinize the reliability of data.

This program will be open-ended in that there is no restriction in the choice of instruments that can be incorporated. At present there is no intention to develop new instrumental techniques; rather, commercially available instruments will be repackaged and modified. An effort will be made to interest manufacturers in producing their instruments in standardized, readily interchangeable packages. It has been visualized that an important part of the program will be an attempt to commercialize the results. 


\section{STANDARDIZATION}

As noted in the discussion of Figure 1, packaging will be done in such a way that instruments can be mechanically interfaced at the choice of the experimenter and without restriction on their selection. This has been sketched as a series of packages of uniform cross-section but differing widths. The ultimate configuration will be a little more complex than this. It would be highly desirable to use a tightly standardized geometry like the widely used "NIM Bin"; whether this will be possible remains to be seen.

In addition to a stacking capability, the ideal geometry would be capable of air shipment without additional packing. since any successful instrument will have already been adapted to the flight environment, this requirement may be achieved in practice without great additional effort. It is also intended that components--if not the entire assembly--will be light and campact enough to allow them to be handled by one person.

One strict ground rule is that the completed assembly will be capable of being installed in the luggage or cargo campartment of a small airplane without structural modifications to the airframe. This implies that the assembled package will have sufficient structural integrity to allow it to be tied down with conventional cargo straps in an unprepared volume. In addition, any shock mounting will be internal to the packages or furnished as separate modules. 
Electrical standardization will be straightforward. We will use a standard format for communication between the microcomputer and instruments, and between the microcomputer and a remote terminal. Such a terminal will be located within reach of the experimenter while the instruments themselves may not be accessible in flight. Data will be processed using software that allows the experimenter wide latitude in the choice of such parameters as real-time display format. Use of a data terminal will also allow operation in an interactive mode wherein such things as sample rates, scale factors and data display are adjusted as the experiment progresses.

\section{AIRCRAFT INTERFACE}

FAA licensing requirements are restrictive enough to have dictated that no significant part of the system will be mounted on the outside of an airplane. For practical purposes, the most we can visualize is a sample inlet tube extending outside the envelope of the airframe. Location is dictated by the fact that air sampling must be done in a region that is not subject to contamination by fuel vapor, engine fumes, products scrubbed from the surfaces by airflow, or exhaust products. For sampling particles it is additionally desirable that the sampled airflow be outside the prop wash. This limits us to mounting sample inlets on the wings of single-engined aircraft at a significant distance from the fuselage or in the nose of a twin. Both possibilties have been explored. Earlier work by NASA favors use of the nose 
compartment of a twin-engined Cessna 402. With such an installation, one can visualize mounting the inlets on a standard or replicated copy of a door or access panel. Replacing an existing component with such a modification could be done by a certified mechanic in a short time. An attractive, but expensive, alternative would be to replace the entire nose cone with one having an inlet in the stagnation region.

Single-engined aircraft installations have been considered for the ubiquitous Cessna 172 as well as for the slightly larger and more powerful 182. The internal geametry of the wing as well as a fortuitous arrangement of cabin ventilating ducts and inspection ports favors the 182. This aircraft is also probably more widely available for charter operations, being more of a "workhorse" than a means of personal transportation. Since the Cessna 182 has a convenient arrangement of inspection ports in the outboard part of the wing, we plan to develop an inlet assembly that can replace an inspection port cover. A sample line will be run in--or in place of--one of the existing ventilation ducts. This line can easily be routed to the luggage compartment aft of the rear seats and will be accessible by removing a single wing root fairing.

Figure 3 shows the installation options. Both Cessna 402 and 182 are sketched. For both, inlets will be mounted outside the boundary layer. In the case of experiments that involve a large number of sensors, the 402 will be preferable--even independent of other considerations--because of its greater payload capacity. (The 402 has an allowable load of over 500 pounds in the nose 


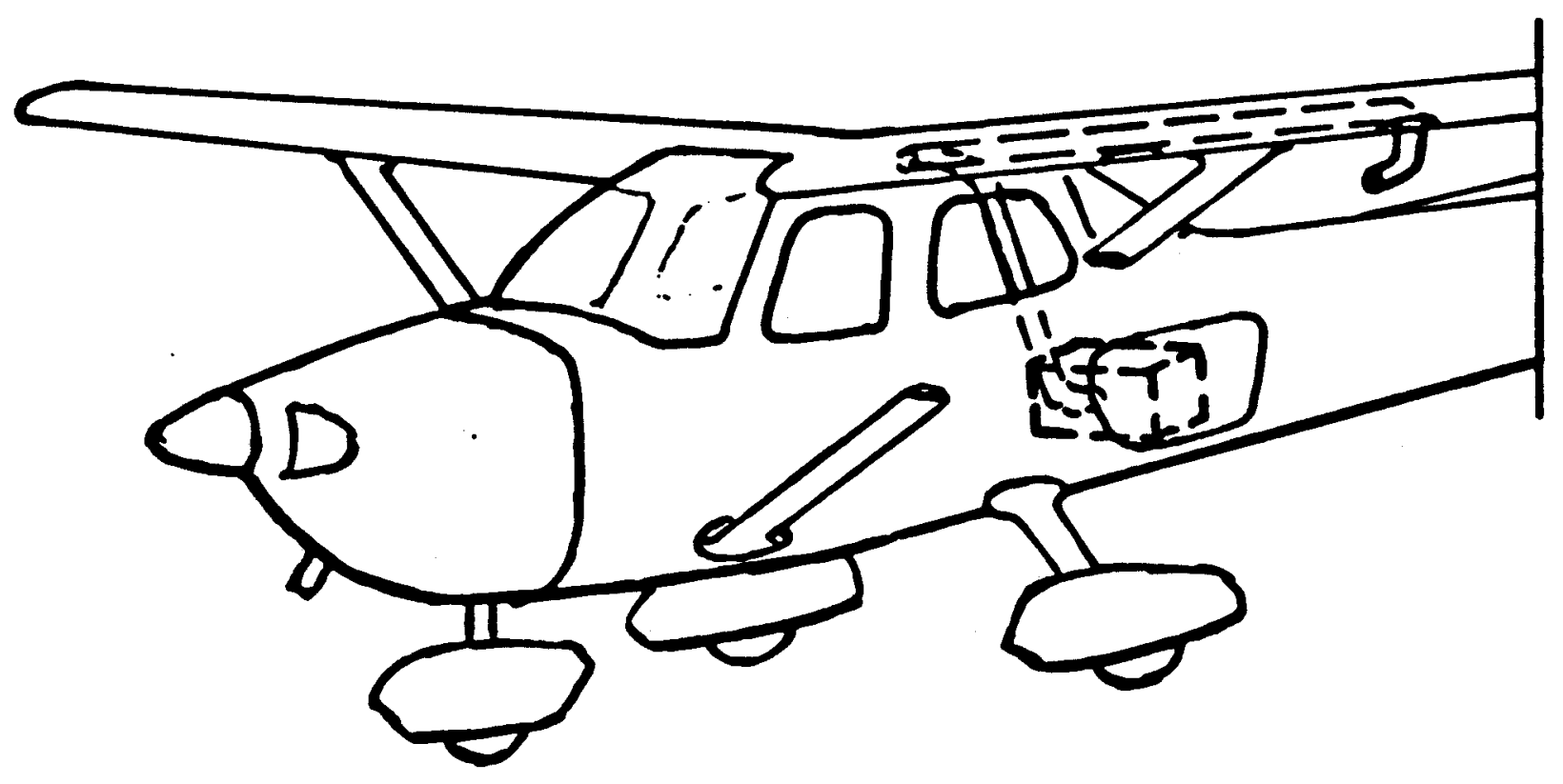

C182 Installation

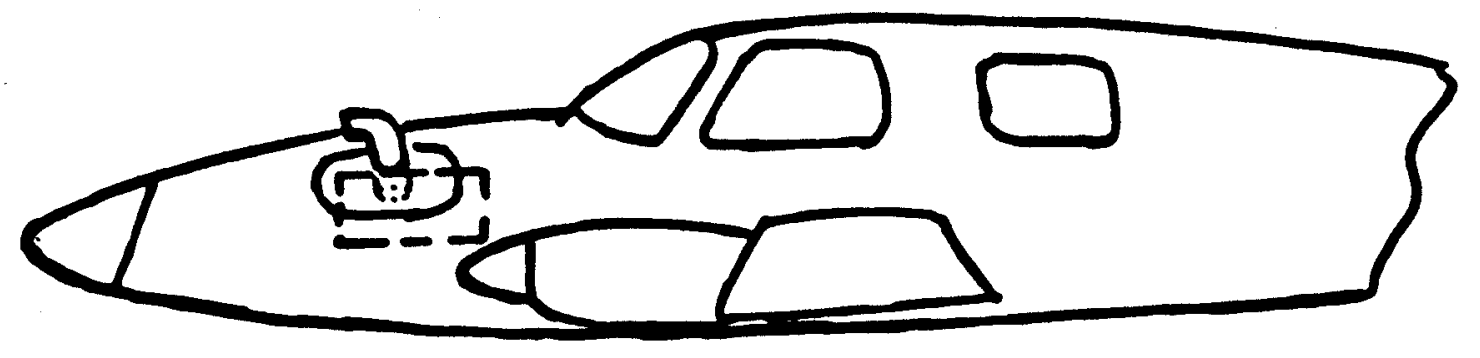

C402 Installation

Figure 3. Aircraft Installations 
section. The maximum weight allowed in the baggage area of a 182 is 200 pounds.)

\section{DATA ACQUISITION AND CONTROL SYSTEM}

Figure 4 shows the overall control system. The central processing unit is a commercial microcamputer. This is a ruggedized and environmentally qualified version of a desktop computer-without most of the peripheral equipment other than a tape transport. Being totally compatible, this can be programed using software developed on the desktop version. The functioning programs can either be entered from tape--using the integral tape transport that will also be used for data logging or, preferably, stored in PROMs.

For our application it is necessary that the microcomputer system be able to communicate with the sensors via a bus that carries command signals as well as data. The IEEE 488 format has already received wide industry acceptance for such applications; in fact, several of the instruments that had already been selected for their other features offer an IEEE 488 port as an inexpensive option. These interface directly with the microcomputer, which also has an IEEE 488 port. With the current avalanche of interest in the application of microprocessors to the control of laboratory equipment, we can be sure that an ever-increasing selection of instruments will become available that can be readily interfaced with data logging and control systems. Should other bus formats 
IEEE 488

Instruments

32

Inst rument

Analog

Inputs

16

Instrument

Digital

Inputs

16

Digital

Control

Lines

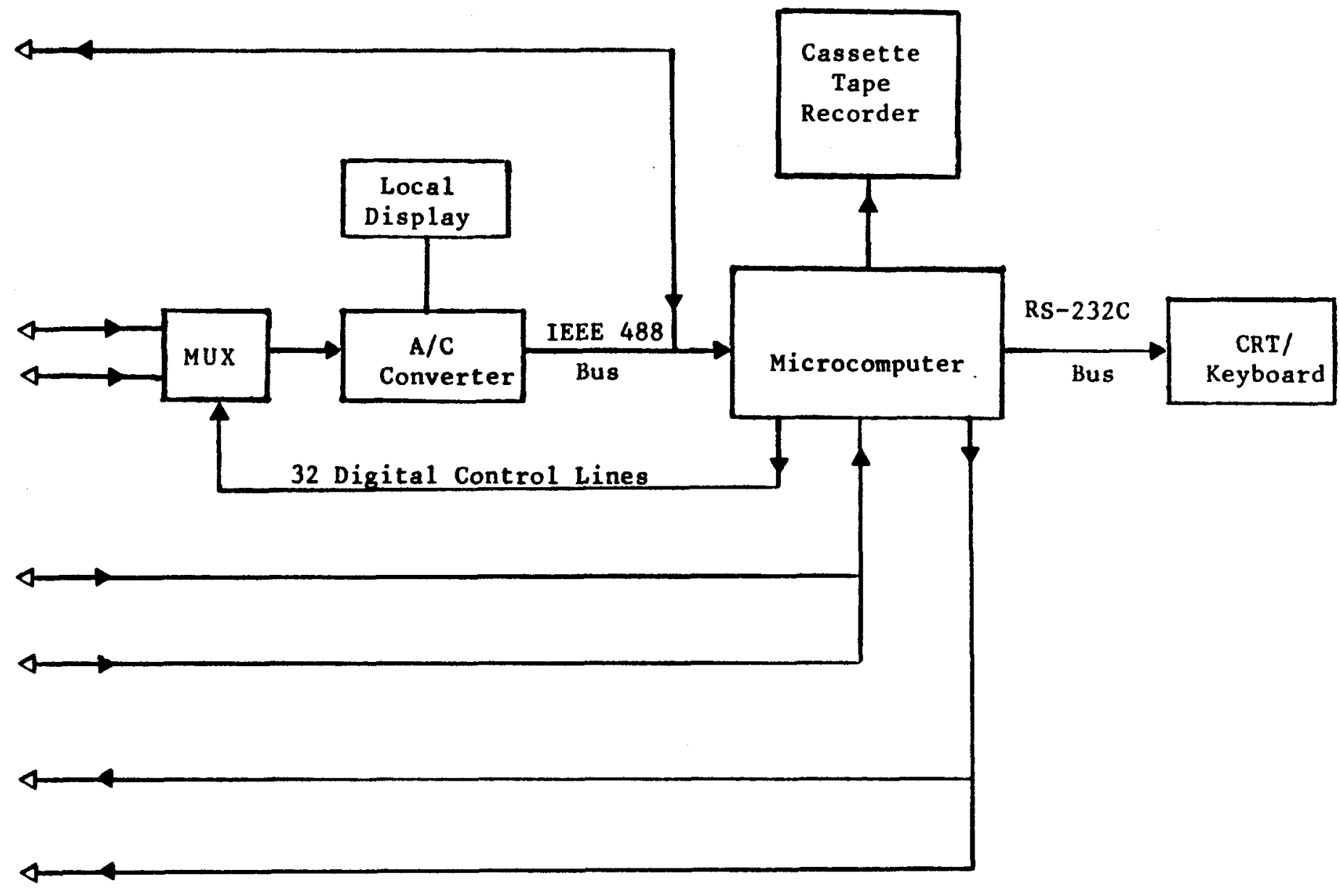

Figure 4. Computer System 
begin to compete, adapating our system to their use will be at most a software development problem.

Another requirement that is equally easy to satisfy is that of ariving and communicating with a remote terminal. The RS-232C (serial) format has becone almost universal for this application. A wide assortment of terminals and displays are available with this format at a naminal price. The chosen computer not only has an appropriate port, it has the inherent capability of driving a long transmission line.

\section{PROTOTYPE SYSTEM COMPONENTS}

The major commercial components of the prototype system are listed in Table 1, wich also gives relevant information concerning cost and physical characteristics. Weights and sizes apply to the equipment as it is commercially furnished. A major part of our effort will be in repackaging and in eliminating unnecessary weights such as AC power supplies.

The Environmental Research Division of Sandia National Laboratories has supported the development of radio navigational equipment that may be incorporated into the flight system at a later date. At present we have a working system based upon commercial aircraft Distance Measuring Equipment (DME). This uses a microprocessor to cycle a DME through a list of FAA navigational ground stations and Sandia-owned stations that can be positioned near the source being investigated. In the first flight application, position data were put into the Rs-232C format 
TABLE 1

SYSTEM COMPONENTS

WEIGHT(1bs) DIMENSIONS(in.) $\operatorname{cosT}(1 / 1 / 1982)$

Microcomputer

10

$6 \times 8 \times 18$

$\$ 2500$

Interface

7

$8 \times 3 \frac{1}{2} \times 7$

1100

Display

5

$\mathrm{n} / \mathrm{a}$

300

Keyboard

3

$\mathrm{n} / \mathrm{a}$

400

$\mathrm{O}_{3}$ Instrument

35

$17 \times 9 \times 23$

6000

co Instrument

45

$17 \times 9 \times 23$

7000

NO $x$ Instrument

20

$7 \times 8 \times 18$

6000

Pump

3

$\mathrm{n} / \mathrm{a}$

300

Power Supply

n/a

$\mathrm{n} / \mathrm{a}$

$\mathrm{n} / \mathrm{a}$

Grab Sampler

5

$\mathrm{n} / \mathrm{a}$

$\mathrm{n} / \mathrm{a}$

Particle Sampler

2

$\mathrm{n} / \mathrm{a}$

$\mathrm{n} / \mathrm{a}$ 
and put on a bus connected to the microcomputer of a helicopterborne experiment. The data were then telemetered in real time to the ground. In the MARSSS application, data would similarly be transmitted by hard wire to the microcomputer and then either recorded on tape or reformatted for telemetry.

A second navigational system that is currently under in-house development at Sandia is the "Minimarker" touched on in Figure 1. This is a small, low-cost ranging system intended for throw-away use in very small marker balloons. This equipment, too, is adaptable to the present problem although its capabilities are limited when compared to the DME system. 


\section{DISTRIBUTION:}

David s. Ballantine

Pollutant Characterization and

Safety Research Division/EV-35

office of Health and

Environmental Research

Ma11 Stop E-201, Germantown

U. S. Department of Bnergy

Washington, DC 20545

A. J. Alkezweeny

Pacific Northwest Iaboratory

P. 0. Box 999

Richland, WA 99352

\section{Sumer Barr}

IOB Alamos National Iaboratory

G-8, MS -588

P. O. Box 1663

Ios Alamos, NM 87544

C. E. Decker

Research Triangle Institute

P. O. BOx 12194

Research Triangle Park, NC 27709

Dr. Russell Dietz

Environmental Chemistry Division

Bldg. 426

Brookhaven National Laboratory

Upton, NY 11973

\author{
R. Evans \\ Environmental Monitoring and \\ Support Laboratory \\ U. S. Environmental Protection \\ Agency \\ P. O. Box 15027 \\ Las Vegas, NV 89114 \\ R. Garber \\ Air quality Branch \\ Tennessee Valley Authority \\ sheffield, AI 35660 \\ N. G11Lan1 \\ Mechanical Engineering Department \\ Nashington Oniversity \\ st. Louis, wo 63130
}

Paul H. Gudiksen

Lawrence Iivermore National Laboratory University of California

P. 0. BOX 808

Itvermore, CA 94550

N. Hester

Enviromental Monitoring and Support Laboratory

U. S. Enviromental Protection Agency

P. O. Box 15027

Las Vegas, NV 89114

Dr. Frank Hudson

Office of Health a Inviromental Research

Department of Inergy

Mail stop $\mathbf{E - 2 0 1}$

Washington, DC 20545

R. Husar

Mechanical Ingineering Department

Mashington Oniversity

st. Lou1s, wo 63130

L. Newman

Brookhaven National Laboratory

B426, 51 Be11 Avenue

Upton, NY 11973

R. Pueschel

Environmental Research Iaboratory

National Oceanic \& Atmospheric

Administration

Boulder, $\infty 080302$

W. E. Wilson, Jr.

U. S. Environmental Protection Agency

Research Triangle Park, NC 27711

4700 E. H. Beckner

4770 G. E. Brandvold

4774 B. D. Zak (25)

4774 B. W. Church

4774 A. I. Jensen

4774 R. O. Woods (5)

8266 S. A. Aas

3141 I. J. Erlckeon (5)

3151 W. I. Garner (3)

3154-3 C. H. Dalin

(for DOE/TIC) (25) 